\title{
UMCLASSIFIED
}
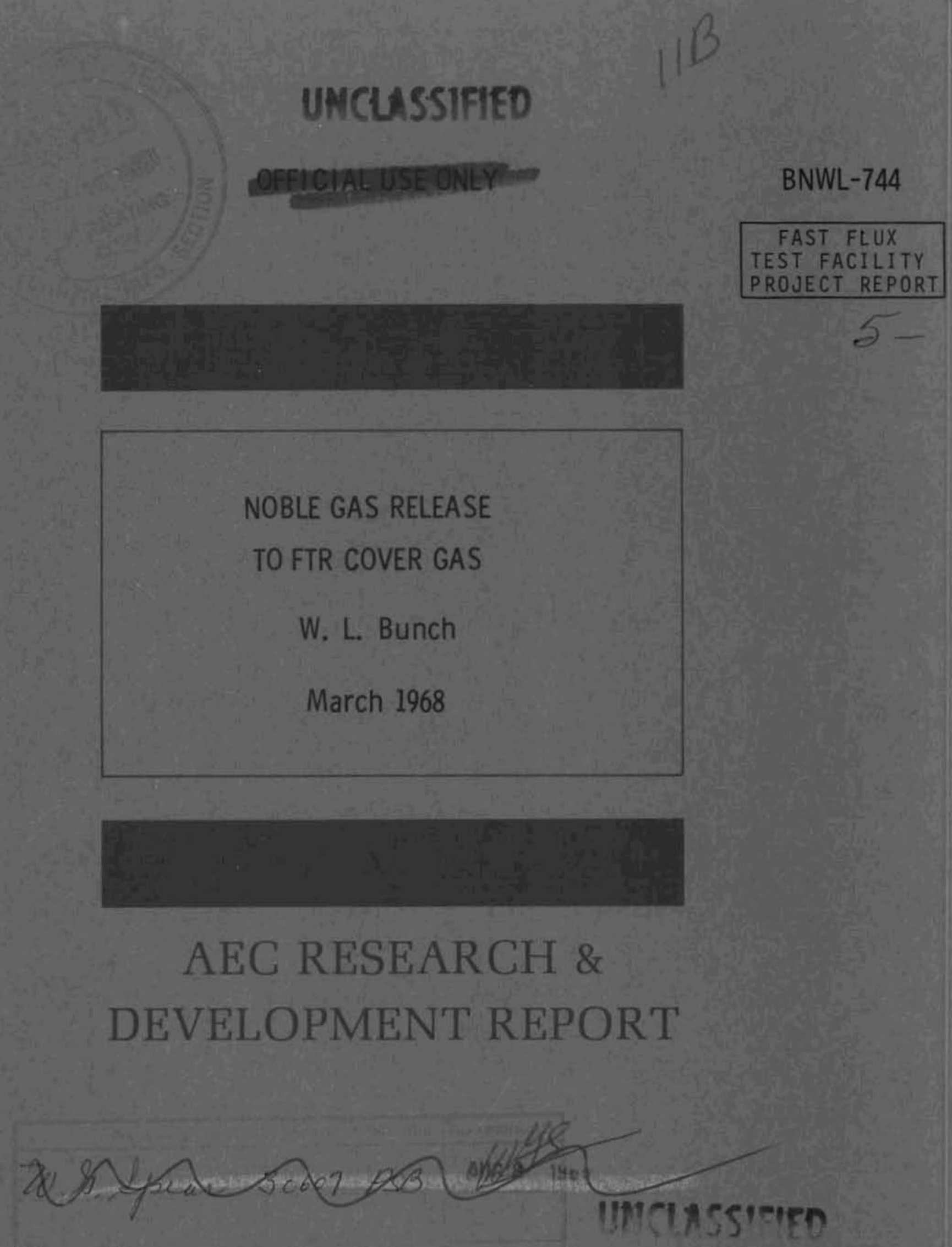
PANWT STATUS

The decument capy, since it is transmitted in advance of patent clearance, is mede-availoble in

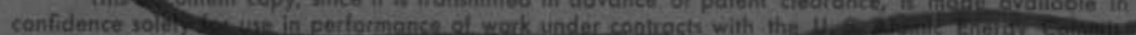

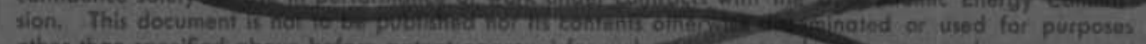
other than ipecified above before pafent opproval for wish rsilfase or use hossesespcured, upon recuest

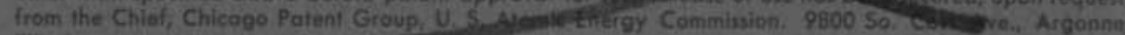
Illinois.

\section{PRELISINARY REPORT}

This report contains information of o preliminory nature prepared in the course of work under Atomic Energy Commission Contract AT(45-1) 1830 . This information is wbject fo cotrection or modifica. tion upon the collinction and evaluation of additionol date.

\section{LEGAL NOTICE}

This report was prepored as an occounl of Government sponsored work, Neither the United Stateh, ner the Commission, nor any person osting on behilf of the Commission:

A. Makes any warrenty of representotion, expressed or implied, with respect to the accuracy, com. pleteness, or usefulness of the information contained in this repoes, or that the use of any informotion, apporatus. method, or process disclesed in this report may not infringe privately owned rights or:

B. Assumes any liabilities with respoct to the use of, or for dainages resulting from the use of any information, opparotus, method, or process disciosed in this report.

As used in the above, "person acting on betralf of the Commission" includes any employee or contracior of the Commission, or employee of such contractor, to the extent that such emplavec or con: fractor of the Commissios, or employee of such controctor prepares, disseminates, or pravides access to any information purvuant to his employment or contract with the Commission, or his employment witi such controctos.

\section{PACIFIC NORTHWEST LABORATORY} RICHLAND, WASHINGTON

operated by

BATTELLE MEMORIAL INSTITUTE

for the

UNITED STATES ATOMIC ENERGY COMMISSION UNDER CONTRACT AT(45-1)-1830 


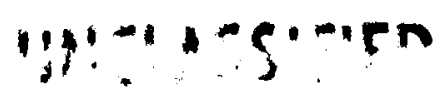

BNWL- 744

\section{7}

TOELD GAS RETEASE TO FTR COVER GAS

by

$$
\text { W. I. Eunch }
$$

Shielding Analysis Unit

IFT Reactor Fhysics Section

Narch 15, 1968

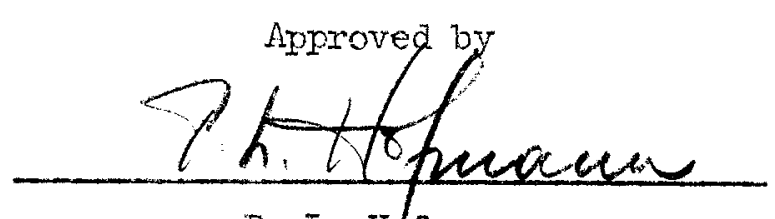

P. I. Hofmann

PAOTITC IORITWEST IABORAIDRY

FICRIAID, WASHIITCTOI 
O.... 
IIAFLE OF CONTENTS

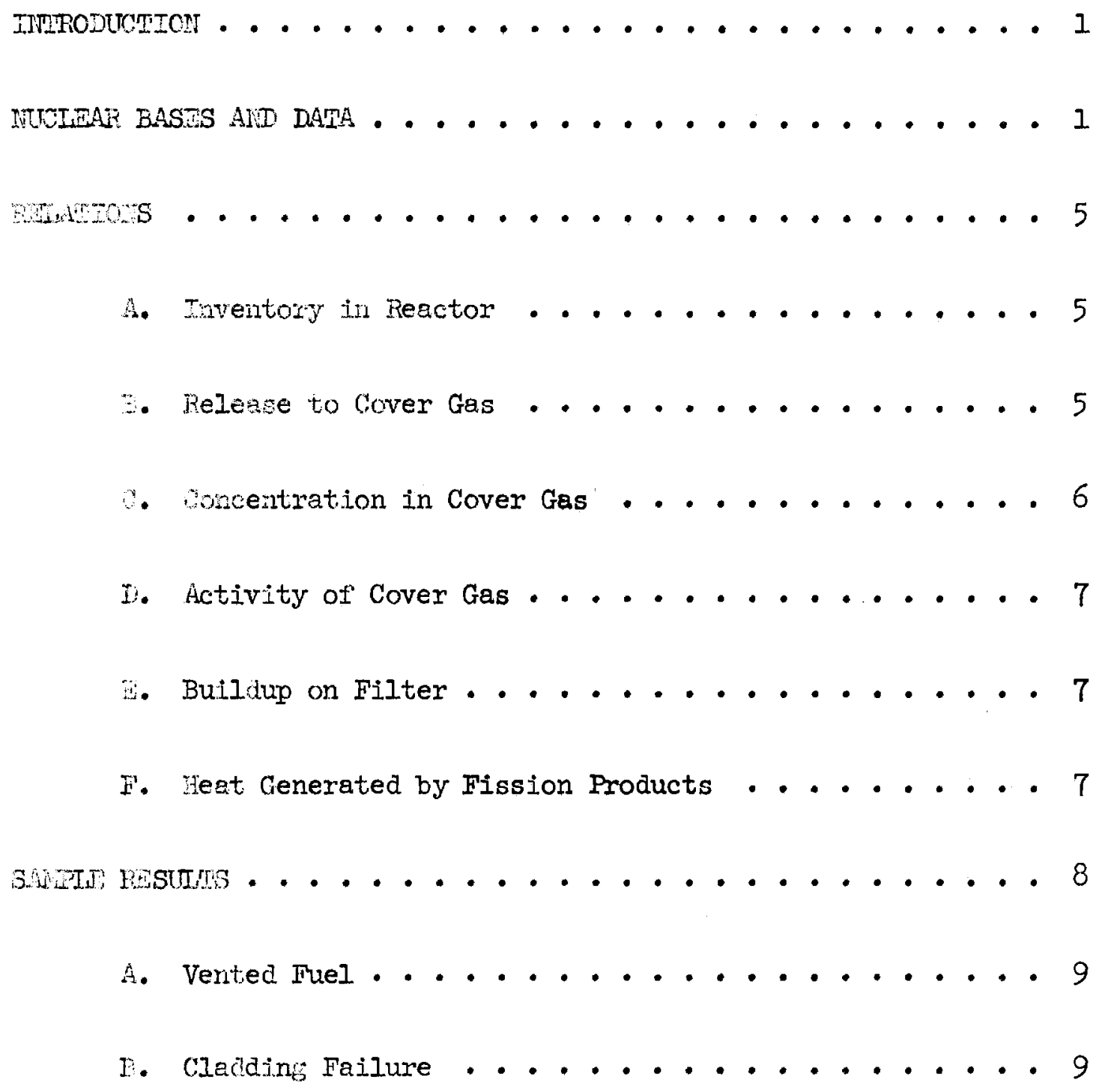


BNWL-744

NOBLE GAS REIEASE TO FIR COVER GAS

W. I. Bunch

INTRODUCTION

An inert cover gas is to be provided for the FTR sodium coolant to prevent oxidation of the liquid metal and suppress inleakage of undesirable impurities. The cover gas needs to be chemically inert to the materials within the sodium system, and should not contribute significantly to the radiation problems associated with the reactor. Cost and availability of the required quantities of gas must also be considered. Gaseous fission products can enter the cover gas, either as the result of a cladding fallure or if vented fuel is used in the reactor. Therefore, the influence of the fission products must be considered in the design of the cover gas system and in the selection of the cover gas. The purpose of the present study is to estimate the release of fission products to the cover gas in order to provide a basis for including this parameter in the conceptual design of the FIR cover gas system.

\section{NUCLEAAR BASES AND DATA}

The noble gases (krypton and xenon) are expected to be the fission products that will be able to traverse the sodium and enter the FIR cover gas in sufficient quantities to influence the design of the cover gas system. The quantities of these gases that enter the cover gas will depend on their production rate within the fuel, their effective holdup time from formation to entrance into the cover gas, and the fraction that escapes with this effective holdup time. This study has been directed primarily at establishing the production rates and the relations that apply. Calculations have been 
included for two simple cases to indicate the important roles of holdup time and release fraction.

Nuclear data for use in evaluating the release of noble gas isotopes to the cover gas system are given in Table I. The tabulated values are defined as follows:

$Y_{i}$ These values are the effective cumulative yield factors (percent) for each isotope or isomeric state considering direct yield factors together with decay chains and branching ratios, but neglecting the possible effect of subsequent neutron transmutations. These cumulative yield factors assume equilibrium conditions exist in the decay chain. Because of the short half lives of most precursors, the values would be attained after a few hours of operation. However, in the case of ${ }^{13}{ }^{1} \mathrm{Xe}$, several weeks of operation would be required to attain the tabulated value because of the 8.05 day half life of ${ }^{13}$ I. The direct yield factors are based on values presented in $\mathrm{LA}-3383$. (1) The effect of branching ratios through isomeric states was included by using factors tabulated by Gumprecht for use with RIBD. (2)

$P_{i}$ The effective curnulative production rate of each isotope or isomeric state has been calculated for an operating level of $400 \mathrm{MW}$. The tabulated values are based on an energy release of $215 \mathrm{MeV}$ per fission event, with a resultant conversion factor of $1.16 \times 10^{19}$ fissions per second at $400 \mathrm{MW}$.

(1) C. A. Anderson, Jr., "Fission Product Yields from Fast ( 1 MeV) Neutron Fission of Pu-239," IA-3383, December. 30, 1965.

(2) W. I. Bunch and D. R. Marr, "Fast Reactor Iibrary for use with RIBD," BNWL-CC-868, October 17, 1966. 
Nuclear Data for Noble Gas Fission Product Isotopes (a)

\begin{tabular}{|c|c|c|c|c|c|c|c|}
\hline \multirow[b]{2}{*}{ Krypton } & $\begin{array}{c}Y_{i} \\
\text { Effective } \\
o \\
\text { Cumulative } \\
\text { Yield } \\
\end{array}$ & $\begin{array}{c}\mathrm{P}_{i} \\
10^{17} \text { atoms } / \mathrm{sec} \\
\text { at } 400 \mathrm{MN} \\
\end{array}$ & $\begin{array}{l}{ }^{\tau} \dot{ } \\
\text { Half } \\
\text { Iife, } \\
\text { Days } \\
\end{array}$ & $\begin{array}{c}\lambda_{i}^{d} \\
\text { Decay } \\
\text { Constant } \\
\text { Days }-1 \\
\end{array}$ & $\begin{array}{c}\lambda_{i}^{s} \\
\text { Decay } \\
\text { Constant } \\
\text { Sec }^{-I} \\
\end{array}$ & \multicolumn{2}{|c|}{$\begin{array}{l}\frac{2}{\text { Decay Energy, }} \\
\frac{10^{-13} \text { watt-sec/decay }}{E_{i}^{\beta}}\end{array}$} \\
\hline & & & & & & & \\
\hline $\begin{array}{l}83^{m} \\
83 \\
84 \\
85 \mathrm{~m} \\
85 \\
86 \\
87 \\
88 \\
89 \\
90 \\
91 \\
92 \\
93 \\
94 \\
95\end{array}$ & $\begin{array}{l}0.38 \\
0.38 \\
0.52 \\
0.69 \\
0.13 \\
0.90 \\
1.145 \\
1.392 \\
1.598 \\
1.463 \\
1.071 \\
0.546 \\
0.184 \\
0.040 \\
0.005\end{array}$ & $\begin{array}{l}0.44 \\
0.44 \\
0.60 \\
0.80 \\
0.15 \\
1.04 \\
1.33 \\
1.61 \\
1.85 \\
1.70 \\
1.24 \\
0.63 \\
0.21 \\
0.05 \\
0.006\end{array}$ & $\begin{array}{l}7.75^{-2} \\
\infty \\
\infty \\
1.833^{-1} \\
3.927^{3} \\
\infty \\
5.278^{-2} \\
1.167^{-1} \\
2.222^{-3} \\
3.819^{-4} \\
1.157^{-4} \\
3.477^{-5} \\
2.315^{-5} \\
1.620^{-5} \\
1.157^{-5}\end{array}$ & $\begin{array}{c}8.94^{0} \\
0 \\
0 \\
3.78^{0} \\
1.76^{-4} \\
0 \\
1.211 \\
5.940 \\
3.12^{2} \\
1.814^{3} \\
5.99^{3} \\
1.995^{4} \\
2.99^{4} \\
4.275^{4} \\
5.99^{4}\end{array}$ & $\begin{array}{c}1.035^{-4} \\
0 \\
0 \\
4.37^{-5} \\
2.04^{-9} \\
0 \\
1.40^{-4} \\
6.87^{-5} \\
3.61^{-3} \\
2.10^{-2} \\
6.93^{-2} \\
2.31^{-1} \\
3.46^{-1} \\
4.95^{-1} \\
6.93^{-1}\end{array}$ & $\begin{array}{l}0 \\
0 \\
0 \\
0.46 \\
0.40 \\
0 \\
2.15 \\
0.61 \\
2.23 \\
2.19 \\
2.50 \\
4.37 \\
6.12 \\
4.33 \\
7.32\end{array}$ & $\begin{array}{c}0.066 \\
0 \\
0 \\
0.287 \\
0.0064 \\
0 \\
1.745 \\
3.08 \\
3.63 \\
3.57 \\
3.20 \\
0 \\
0 \\
0 \\
0\end{array}$ \\
\hline Xenon & & & & & & & \\
\hline $\begin{array}{l}131^{\mathrm{m}} \\
131 \\
132 \\
133^{\mathrm{m}} \\
133 \\
134 \\
135^{\mathrm{m}} \\
135 \\
136 \\
137 \\
138 \\
139 \\
140 \\
141 \\
142\end{array}$ & $\begin{array}{l}0.024 \\
3.40 \\
4.55 \\
0.114 \\
5.70 \\
6.449 \\
1.85 \\
6.843 \\
6.887 \\
6.496 \\
4.968 \\
2.987 \\
1.443 \\
0.510 \\
0.110\end{array}$ & $\begin{array}{l}0.03 \\
3.94 \\
5.28 \\
0.12 \\
6.62 \\
7.48 \\
2.14 \\
7.94 \\
8.00 \\
7.54 \\
5.76 \\
3.46 \\
1.67 \\
0.59 \\
0.13\end{array}$ & $\begin{array}{c}1.20^{1} \\
\infty \\
\infty \\
2.30^{0} \\
5.27^{0} \\
\infty^{\infty} \\
1.117^{-2} \\
3.833^{-1} \\
\infty \\
2.708^{-3} \\
9.722^{-3} \\
4.745^{-4} \\
1.852^{-4} \\
1.968^{-5} \\
1.736^{-5}\end{array}$ & $\begin{array}{c}5.77^{-2} \\
0 \\
0 \\
3.01^{-1} \\
1.31^{-1} \\
0 \\
6.23^{0} \\
1.807^{0} \\
0 \\
2.56^{2} \\
7.121 \\
1.463 \\
3.743 \\
3.52^{4} \\
3.99^{4}\end{array}$ & $\begin{array}{c}6.68^{-7} \\
0 \\
0 \\
3.48^{-6} \\
1.51^{-6} \\
0 \\
7.21^{-5} \\
2.09^{-5} \\
0 \\
2.96^{-3} \\
8.25^{-4} \\
1.69^{-2} \\
4.33^{-2} \\
4.07^{-1} \\
4.62^{-1}\end{array}$ & $\begin{array}{l}0 \\
0 \\
0 \\
0 \\
0.16 \\
0 \\
0 \\
0.496 \\
0 \\
2.37 \\
1.54 \\
3.20 \\
1.75 \\
3.78 \\
2.72\end{array}$ & $\begin{array}{c}0.262 \\
0 \\
0 \\
0.374 \\
0.131 \\
0 \\
0.85 \\
0.418 \\
0 \\
1.60 \\
0.67 \\
0.64 \\
0 \\
0 \\
0\end{array}$ \\
\hline
\end{tabular}

(a) Note abbreviation that $7.75^{-2}=7.75 \times 10^{-2} ; 3.78^{0}=3.78 ; 3.927^{3}=3.927 \times 10^{3}$; eto. 
$\tau_{i}$ The half life of the isotope or isomeric state, in days. These values were also taken from the RIBD libraxy. (2)

$\lambda_{i}^{d}$ The decay constant for each isotope, in reciprocal days. The decay constant is equal to 0.693 divided by the half life. The activity (or nurnber of radioactive nuclei) of a particular species decreases exponentially with time; i.e. as $\exp \left(-\lambda_{i} t\right)$, where the time $t$ is measured in the same units as the decay constant.

$\lambda_{i}^{s}$ The decay constant in reciprocal seconds, for convenience in considering the effect of short decay time.

$E_{i}^{\beta}$ The average energy associated with the beta rays emitted as the nucleus decays. The average beta ray energy is significantly less than the maximum measured energy for a given species. The relationship between the maximum and the average energy is dependent on the degree of forbiddeness of the transition. The rest of the energy is presumably carried away by the neutrino and does not contribute to the local heat removal problem. Values were taken from the RIBD library developed by Gumprecht.(2) For short half-life isotopes in which experimental data is incomplete, all of the energy is assumed to be associated with the betas and none with the gammas.

$\mathrm{E}_{i}^{\gamma}$ The average energy associated with the gamma radiation emitted as a result of the disintegration process. This energy can be associated either with a complex or simple spectrum. The total energy values were taken from the RIBD library. 


\section{REIATIONS}

\section{A. Inventory in Reactor}

Under the assumptions discussed above for the cumulative yield factor, the radioactive content of the core will reach an equilibrium value equal to the production rate. That is, the number of radioactive nuclei of a particular species will continue to increase until the decay rate equals the production rate. Such a condition should exist after a few weeks of operation for all of the radioactive species but ${ }^{85} \mathrm{Kr}$. The ground state of this isotope has a half-life of 10.76 years; hence, the inventory will increase throughout the fuel irradiation. In general, the radioactive inventory of the $i^{\text {th }}$ species, $I_{i}^{*}$, is given by

$$
I_{i}^{*}=\frac{P_{i}}{\lambda_{i}}\left[1.0-\exp \left(-\lambda_{i} T\right)\right]
$$

where $T$ is the length of time the fuel has been irradiated. After a few weeks of operation, the term in brackets is essentially equal to unity for all species but ${ }^{85} \mathrm{Kr}$, and

$$
I_{i}^{*}=P_{i} / \lambda_{i}
$$

For the stable species, the inventory continues to increase throughout the irradiation and is given by

$$
I_{i}=P_{i} T
$$

where $T$ must be in seconds for $P_{i}$ in atoms per second.

B. Release to Cover Gas

The rate at which noble gas might be expected to enter the cover gas can be estimated by considering an effective holdup time. It is presumed the 
fission products will be generated within the reactor. At the instant a noble gis nucleus is generated, it is free to begin a tortuous path to the cover gas that takes an effective length of time $H$. If the nucleus decays prior to reaching the cover gas, it is no longer a noble gas and its journey ends short of the cover gas. Ihus, the rate at which radioactive noble gas nuclei reach the cover is

$$
\mathrm{N}_{i}^{*}=f \mathrm{P}_{i} \exp \left(-\lambda_{i} \mathrm{H}\right)
$$

where $f$ is the fraction of the nuclei generated that have an escape path with this effective holaup time. For the stable isotopes, the equilibrium release rate to the cover gas is

$$
N_{i}:=P_{i}
$$

independent of the holdup time.

C. Concentration in Cover Gas

The concentration of noble gas fission products in the cover gas can be calculated for specific systems. The simplest case is that of a single pass system in which fresh gas enters the system continuously at a flow rate $F$ cubic centimeters per second, and leaves the system at the same rate carrying along the fission products. In practice, the gas could be filtered to remove the fission products and then released, or could be filtered, retained, and reused. For this simple system, the concentration of each isotope in the cover gas is

$$
Q_{i}=N_{i} / F \text { or } Q_{i}^{*}=N_{i}^{*} / F
$$

where the $Q^{\prime}$ s are in atoms per cubic centimeter. 


$$
-7-\quad \text { BNWL- } 744
$$

\section{Activity of Cover Gas}

The specific activity of the cover gas will be directly proportional to the concentration of radioactive nuclei:

$$
g_{i}=\frac{Q_{i}^{*} \lambda_{i}}{3.7 \times 10^{4}}\left(\mu C_{i} / \mathrm{ml}\right)
$$

The radiological hazard associated with this concentration can be estimated by considering (i) the gamma field associated with a specific geometry array of the contained gas, and (ii) the maximum permissible concentration that can safely be released to habitable areas, as defined by appropriate established criteria。

\section{E. Buildup on Filter}

If the cover gas is passed through a perfect filter that removes all of the noble fission products, the number of atcms trapped on the filter is given by:

$$
\begin{aligned}
& B_{i}(t)=N_{i} t \text { (stakle ruclei, } t \text { in seconds) } \\
& B_{i}^{*}(t)=\frac{N_{i}^{*}}{\lambda_{i}^{*}}\left[1.0-\exp \left(-\lambda_{i} T\right)\right] \text { (radioactive nuclei) }
\end{aligned}
$$

where $N^{\prime}$ s are related to the production rate as described previously. After a few weeks of operation the term in brackets need only be considered for ${ }^{85} \mathrm{Kr}$. In the relation for $B_{1}^{*}(t)$, the transport time in the cover gas can be included by incrementing the holdup time $H$ to include this additional path.

F. Heat Generated by Fission Droducts

If it is assumed all of the radioactive fission products remain trapped in the filter, the heat generation rate in the filter can be obtained from the product of the disintegration rate and the average energy release per disintegration. The disintegration rate is $B_{i}^{*}(t) \lambda_{i}^{s}$. Essentially all of the beta energy would be deposited within the filter near the point of 
disintegration. The gamma energy would be spatially distributed in a manner dependent on the gamma energy spectrum for the specific isotope and the geometric arrangement of materials in the filter. To a first approximation it can be assumed the gamma energy is also deposited at the point of disintegration, if a conservative estimate of the cooling requirements for the filter is desired. A practical filter system will probably consist of a number of separate filters in series. Each of the filters retains the gas for a finite length of time, after which it escapes to the following f'ilter (if it has not already decayed). The amount of energy dissipated in each filter depends on the length of time the gas is retained in each. Because of half life, the contribution of each isotope must be determined separately. If each of the filters in a series system retains the gas for the same length of time $t_{f}$, then the equilibrium decay rate on the $n$-th filter is given by

$$
D_{i}^{*}=B_{i}^{*} \lambda_{i} \exp \left[-(n-1) \lambda_{i} t_{f}\right]\left[1.0-\exp \left(-\lambda_{i} t_{f}\right)\right]
$$

A sufficient number of filters would need to be employed in series such that the amount of radioactive gas leaving the last filter was tolerable. This implies that essentially all of the decay energy would be deposited within the filter system.

\section{SAMPLE RESUITSS}

Thro sample calculations have been made to illustrate the use of the tabulated nuclear data and the relations defined. The first case is that of vented fuel, while the second is for an assumed cladding failure in nonvented fuel. 


\section{A. Vented Fuel}

It was assumed that all of the fuel generating $400 \mathrm{MW}$ of power would be vented to allow the noble gas to escape to the cover gas $(f=1.0)$. To eliminate the effect of short term trensient effects prior to saturation of the decay chains of interest, it was assuned the reactor had operated for about 115 days or $10^{7}$ seconas. After this length of time all of the radioactive isolopes would be efrectively saturated except for ${ }^{85} \mathrm{Kr}$, which woula have attained about $2 \%$ of its saturated value. It was iurther assumed that a holdup time of 5 days would exist for the transfer of a noble gas nucleus from its point of formation in the core to the cover gas. A cover gas flow rate of $10^{4}$ cubic centimeters per second was assumed. Results of the calculations for isotopes of interest are given in Table II. The contribution of the short half-lived isotopes is negligible because of the holdup time. Cover gas activity and decay heat to the filter would be due primarily to $133 \mathrm{Xe}$ for these assumed conditions.

B. Cladding Failure

A value of $10^{-6}$ was assumed for $f$ to indicate the fractional quantity of naterial located within the vjcinity of the cladding failure and thus able to contribute. As before, it was assumed the fuel had operated for 115 days prior to the fajlure, and the cover flow rate was $10^{4}$ cubic centimeters per second. An effective holdup time of 10 seconds was used. The cladding failure would initially release the existing inventory of stable gas, after which the "equilibrium" values of Table III are calculated to apply. The initial inventory for the example case would be the product of the 
Vented Fuel

Assumptions: $t=115$ days, $H=5$ days, $f=1.0, F=10^{4} \mathrm{~cm}^{3} / \mathrm{sec}$

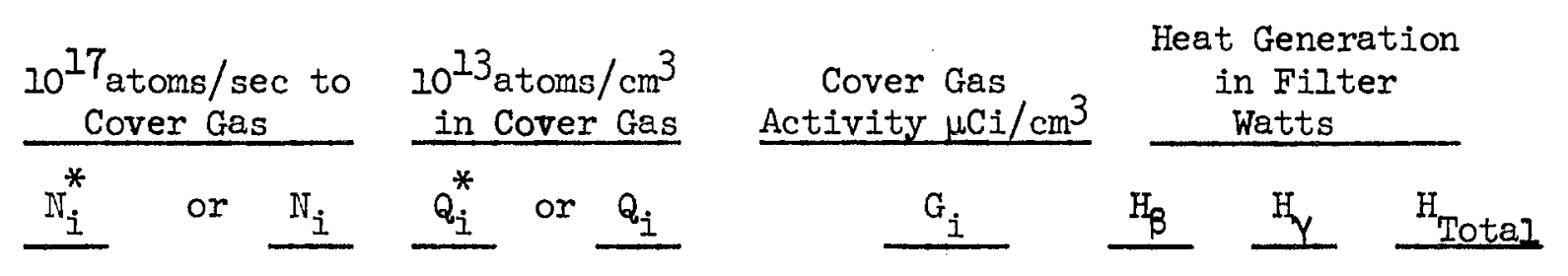

Krypton

\begin{tabular}{|c|c|c|c|c|c|c|c|}
\hline $\begin{array}{l}83 \\
84\end{array}$ & & $\begin{array}{l}0.44 \\
0.60\end{array}$ & $\begin{array}{l}0.44 \\
0.60\end{array}$ & -2 & & & \\
\hline $\begin{array}{l}85 \\
86\end{array}$ & 0.15 & $1.04^{0.15}$ & 1.04 & 8.25 & 12.00 & 0.19 & 12.19 \\
\hline
\end{tabular}

\section{Xenon}

\begin{tabular}{|c|c|c|c|c|c|c|c|c|}
\hline $131^{m}$ & 0.0225 & & 0.0225 & & 4.06 & 0 & 58.9 & 58.9 \\
\hline 131 & & $\begin{array}{l}3.94 \\
5.38\end{array}$ & & $\begin{array}{r}3.94 \\
5.28\end{array}$ & & & & \\
\hline $\begin{array}{l}13 c \\
133^{m} \\
133\end{array}$ & $\begin{array}{l}0.0265 \\
3.44\end{array}$ & & $\begin{array}{l}0.0265 \\
3.44\end{array}$ & & $\begin{array}{l}2.49^{1} \\
1.40^{3}\end{array}$ & $\begin{array}{c}0 \\
5510\end{array}$ & $\begin{array}{l}99.1 \\
4510\end{array}$ & $\begin{array}{l}99.1 \\
10,020\end{array}$ \\
\hline $\begin{array}{l}134 \\
135\end{array}$ & 0.0009 & & 0.0000 & 7.48 & $5.09^{\circ}$ & 4.47 & 3.76 & 8.23 \\
\hline 136 & & 8.00 & & 8.00 & & & & \\
\hline
\end{tabular}

Note: Superscript $m$ denotes metastable state 
Table III

\section{Cladding Failure}

Assumptions: $t=115$ days, $H=10$ seconds, $f=10^{-6}, F=10^{4} \mathrm{~cm}^{3} / \mathrm{sec}$
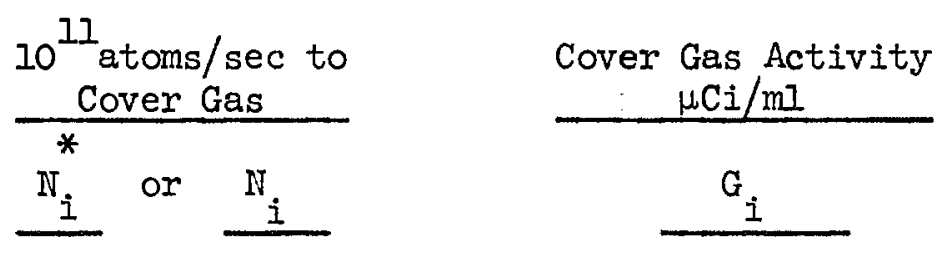

Maximum Heat Generation in Filter Watts
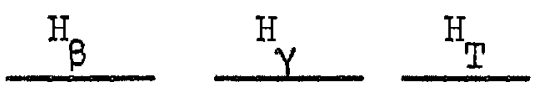

Krypton

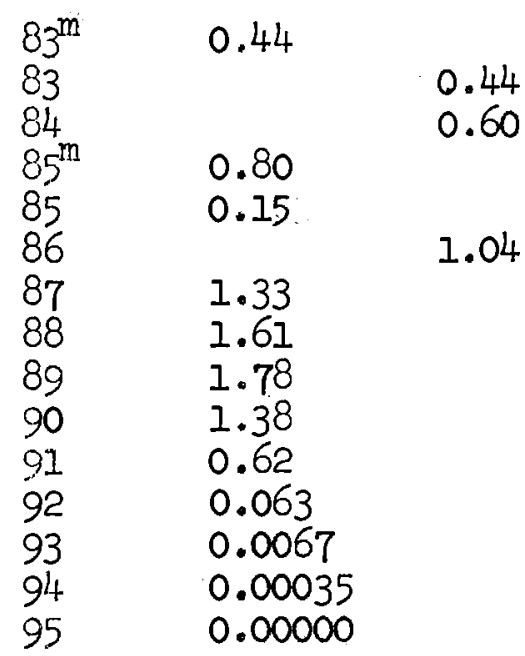

$$
0.0123
$$

0.00945

0.0503

0.0299

1.74

7.82

11.6

3.93

0.627

0.0468

$\sim 0$

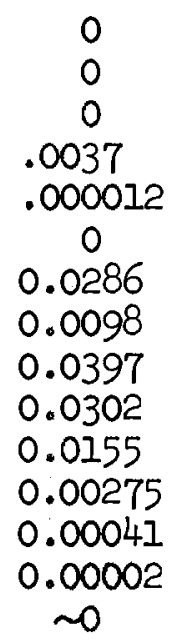

.00029

0.00029

$\begin{array}{lll}0 & 0 \\ 0 & 0\end{array}$

.0023

0.0060

$\sim 0.000012$

$\begin{array}{cc}0 & 0 \\ .0232 & 0.0518 \\ .0496 & 0.0594\end{array}$

.0646

0.1043

.0493

0.0795

.0198

0.0353

$0 \quad 0.00275$

$0 \quad 0.00041$

$0 \quad 0.00002$

$\sim 0$

\section{Xenon}

$\begin{array}{lll}131^{m} & 0.03 & \\ 131 & & 3.94 \\ 132 \mathrm{~m} & & 5.28 \\ 133^{2} & 0.12 & \\ 133 & 6.62 & \\ 134 & & 7.48 \\ 135^{\mathrm{m}} & 2.14 & \\ 135 & 7.94 & \\ 136 & & 8.00 \\ 137 & 7.31 & \\ 138 & 5.71 & \\ 139 & 2.92 & \\ 140 & 1.08 & \\ 141 & 0.0081 & \\ 142 & 0.0013 & \end{array}$

$$
\left(5.42^{-6}\right)
$$

$\left(1.13^{-4}\right)$

0.027

0.0417

0.0449

0
0
0
0
0.0106
0
0
0.0394
0
0.173
0.0879
0.0934
0.0189
0.00031
0.00004

.00008

0.00008

5.85

1.27

13.4

12.6

0.0891

0.0162

$\begin{array}{cc}0 & 0 \\ 0 & 0 \\ .00045 & 0.00045 \\ .0087 & 0.0193 \\ 0 & 0 \\ .0182 & 0.0182 \\ .0332 & 0.0726 \\ 0 & 0 \\ 0.117 & 0.290 \\ 0.0382 & 0.1261 \\ 0.0187 & 0.1121 \\ 0 & 0.0189 \\ 0 & 0.00031 \\ 0 & <0.00004\end{array}$

Note: Superscript $m$ denotes metastable state 
tabulated production rates and the assumed operating time of $10^{7}$ seconds. Thus, for example, the inventory of $136 \mathrm{Xe}$ would be $\sim 8.0 \times 10^{18}$ atoms. It can be seen that the short half-lived isotopes are dominant; thus, the results are sensitive to the assumed holdup time. 
30 U. S. Atomic Energy Commission Division of Reactor Dev \& Tech

M Shaw, Director, RDT Asst Dir for Nuclear Safety Analysis \& Evaluation Br, RDT:NS Environmental \& Sanitary Engrg $\mathrm{Br}, \mathrm{RDT}: \mathrm{NS}$ Research \& Development Br, RDT:NS Asst Dir for Plan Engrg, RDT Applications \& Facilities Br, RDT:PE Components $\mathrm{Br}$, RDT:PE

Instrumentation \& Control $\mathrm{Br}$, $\mathrm{RDT}: \mathrm{PE}$ Systems Engineering $\mathrm{Br}, \mathrm{RDT}: \mathrm{PE}$

Asst Dir for Program Analysis, RDT Asst Dir for Project Mgmt, RDT Liquid Metals Projects Br, RDT: PM FFTF Project Manager, RDT: FM (3) Asst Dir for Reactor Engrg Control Niechanisms $\mathrm{Br}, \mathrm{RDT}: \mathrm{RE}$ Core Design $\mathrm{Br}, \mathrm{RDM}: \mathrm{RE}$

DE Emon

NE Toàreas

Fuel Fabrication $\mathrm{Br}, \mathrm{RDT}: \mathrm{RE}$

Fuel Handling $\mathrm{Br}$, $\mathrm{RDT}: \mathrm{RE}$ Reactor Vessels $\mathrm{Br}, \mathrm{RDT}: \mathrm{RE}$ Asst Dir for Reactor Tech Chemistry \& Chemical. Separations

$\mathrm{Br}_{8} \mathrm{RDT}: \mathrm{RT}$ (2)

Fuels \& Materials Br, RDT:RT Reactor Physics $\mathrm{Br}_{3}$ RDT:RT

Special Technology $\mathrm{Br}_{2}$ RDT: RT

1 AEC Chicago Patent Group

GH Iee, Chief

Patents

RK Sharp

1 AEC Idaho Operations Office Nuclear Technology Division

CW Bills, Director

4 AEC Richland Operations Office FFTF Project Office ( 2 )

Engineering \& Construetion Div (1) JM Shivley 
1 AEC San Francisco Operations Office

Director, Reactor Division

$4 \quad$ AEC Site Representatives - PNI

PG Holsted (2)

IR Lucas

AD Totin

$4 \quad$ AEC Site Representatives

Argonie National Laboratory

Atomics International

Atomic Power Devejopment Assoc.

General Electric Co.

2 Argonne National Laboratory

RA Jaross

IMFBR Program Office

2 Atomics International

IE G.Iasgow

Iiquid Metal Dngrg Center

RW Dickinson

1 Atomic Power Development Assoc.

$$
\text { BVD Farris }
$$

2 Babcock \& Wilcox Co.

Atomic Energy Division

SH Esleeck

Boiler Division

TE Farrell

1 Combustion Engineering

1000 MWe Foilow on Study

WP Staker, Project Manager

2 General Dynamics Corp.

Ceneral Atomic Dj.

D Coburn.

4 General Electric Co.

Advanced Products Operation

Kax' Cohen (3)

I Iaho Nuclear Corporation

DR deBoisbiaric

1 PNL Representative

INA HiII (ZPR-III) 
1 Stanford University

Nuclear Division

Division of Mechanical Engrg

R Sher

5 Westinghouse Electric Corp.

Atomic Power Division

Advanced Reactor Systems

JCR Kelly

30 Battelle Northwest

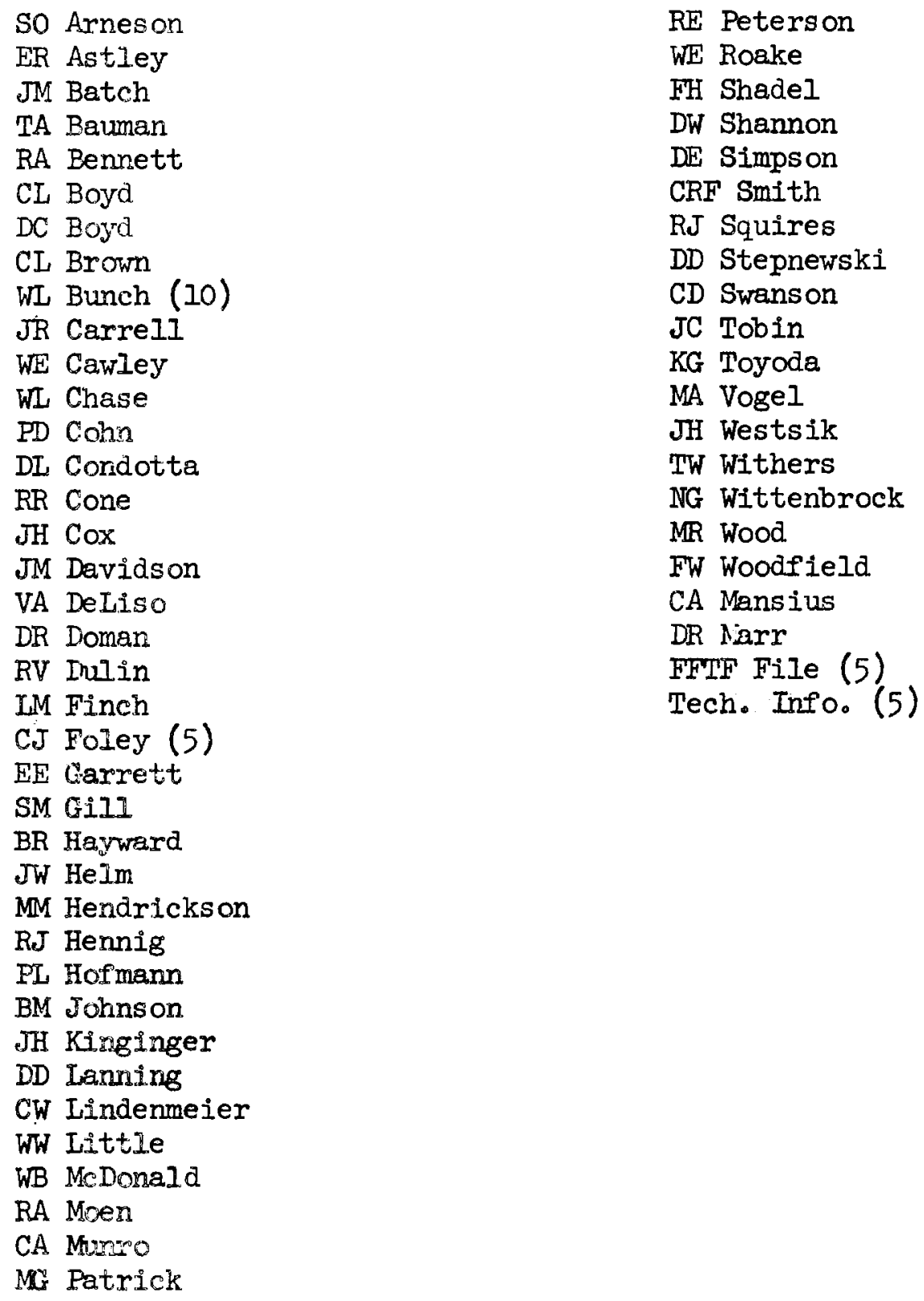

RE Peterson

WE Roake

FH Shadel

DW Shannon

DE Simpson

CRF Smith

RJ Squires

DD Stepnewski

CD Swanson

JC Tobin

KG Toyoda

MA Vogel

$\mathrm{JH}$ Westsik

TW Withers

NG Wittenbrock

MR Wood

FW Woodfield.

CA Mansius

DR Narr FFTF File (5)

Tech. Info. (5) 